\title{
IV. Atatizent.
}

\section{Die Dogelwarte Rolfiten.}

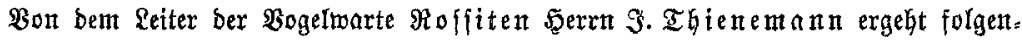
ber $\mathfrak{A} u$ fruf $\mathfrak{m i t}$ ber $\mathfrak{B}$ itte $\mathfrak{u m}$ mỏglidfte $\mathfrak{B e r b r e i t u n g : ~}$

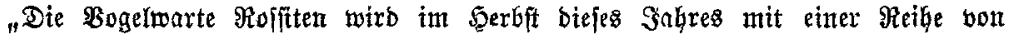

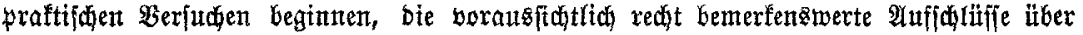

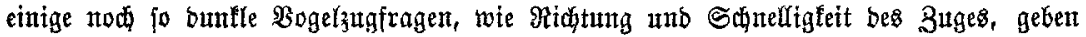
fönner.

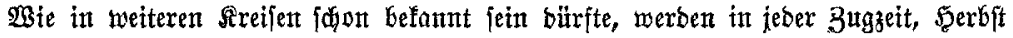

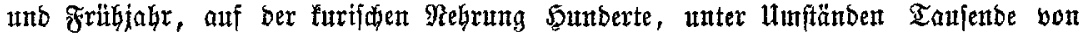
Frähen von ben Eingeborenen zu Speifegtwecten mit Reţen gefangen. Won biefen

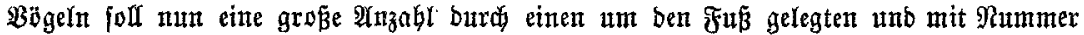
unb Sahreszahl berfehenen Mietallring gezeidinet unb Dann fofort wieber in Fretheit ge= fest werben. Die Erbentung polder gezeidinetent Iiere wixb ftets intereffante Sdyliffe

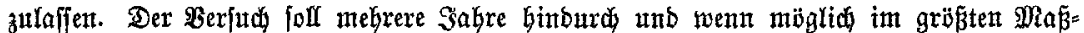
ftab fortgejetzt werben. WGenn wir bann erft Sumberte, ja - falfs bie Mittel ber Station

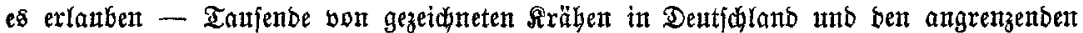

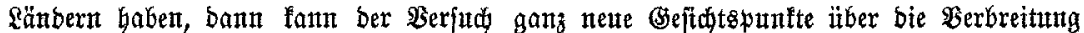

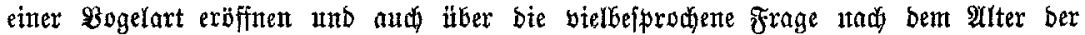
Bögel $\mathfrak{A} u f f \mathfrak{d} l$ luf geben.

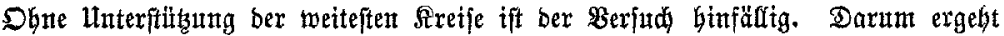

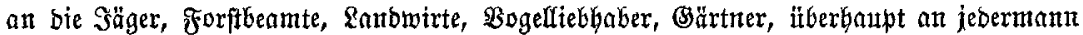

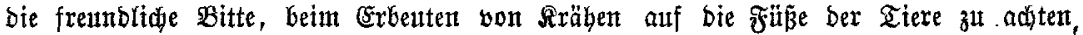

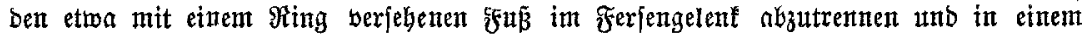

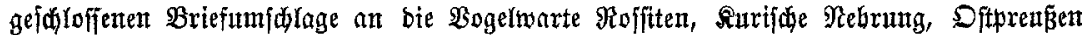

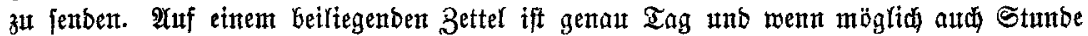

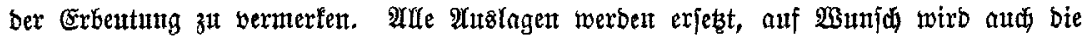
Sräbe bezathlt.

$\Im \mathfrak{m}$ befonderen ridte id meine Bitte an bie Serren Sanbwirte, bie auf ihren

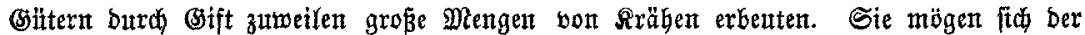

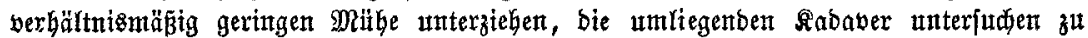
laffen. über bie Refultate woirs jeinerzeit beridgtet werben. Die gezedofneten Bögel werben namentfid $\mathfrak{R}$ ebelfrähen, banteben and Saatfrähen jein."

\section{V. $\mathfrak{A} \mathfrak{n} \mathfrak{k} \mathfrak{i} \mathfrak{g} \mathfrak{H}$.}

Dorlejungen an forfitlithen Gochifhulen im Sommerfemefter 1904. forftlithe Kodhichule Zlifhaffenburg.

Beginn ber $\mathfrak{B o r l e j t u g e n}$ ant 14. YTpril 1904.

Dberforftrat Dr. v. Fürft: Forftencyflopäbie (Forffiduk), Forfteinridutung tut

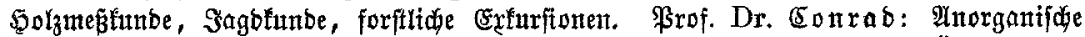

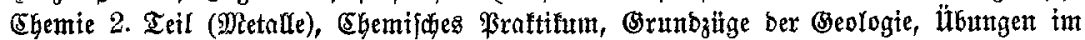
Beftimmen von Mineralien, geologifơe Exturftonen. Prof. Dr. Spangenberg: 3oologie 2. Teil, Smjeftenfunbe, zoologif Dr. Dingler: Botanif 2. Teil, Stftematil ber büheren Getweddfe, ingbefonbere ber 